\title{
Effect of castration method on neurohormonal and electroencephalographic stress indicators in Holstein calves of different ages
}

\author{
J. C. Dockweiler, ${ }^{\star}$ J. F. Coetzee,† L. N. Edwards-Callaway,ł N. M. Bello,§ H. D. Glynn,\# K. A. Allen, * \\ M. E. Theurer,II M. L. Jones, T K. A. Miller,\# and L. Bergamasco**1 \\ *Department of Clinical Sciences, College of Veterinary Medicine, Kansas State University, Manhattan 66506 \\ †Veterinary Diagnostic and Production Animal Medicine, College of Veterinary Medicine, lowa State University, Ames 50011 \\ $\ddagger 1770$ Promontory Circle, Greeley, CO 80634 \\ §Department of Statistics, \\ \#Department of Animal Sciences and Industry, and \\ IIDepartment of Diagnostic Medicine and Pathobiology, College of Veterinary Medicine, Kansas State University, Manhattan 66506 \\ TDepartment of Large Animal Clinical Sciences, College of Veterinary Medicine, Texas A\&M University, College Station 77843 \\ ${ }^{* *}$ College of Agriculture and Life Sciences, Animal and Poultry Sciences Department, Litton Reaves Hall, Virginia Polytechnic Institute \\ and State University, Blacksburg 24061
}

\section{ABSTRACT}

As public concern for food animal welfare increases, a need to validate objective pain assessment tools exists in order to formulate animal welfare policies and facilitate regulatory approval of compounds to alleviate pain in livestock in the United States. The aims of this study were (1) to compare the physiological response to pain induced by surgical and nonsurgical (band) castration in calves and (2) to elucidate age-related differences in pain response of calves subjected to different castration methods. Seventy-six Holstein bull calves were blocked by age ( $\leq 8$-wk and $\geq 6$-mo-old) and randomly assigned to 1 of 4 treatment groups: control $(\mathrm{n}=20)$, castration by banding $(\mathrm{n}=18)$, cut-and-clamp surgical castration $(\mathrm{n}=20)$, and cut-and-pull surgical castration (n $=18$ ). Measurements included electroencephalogram, heart rate variability, infrared thermography, electrodermal activity, and concentrations of serum cortisol and plasma substance $\mathrm{P}$ before, during, and within 20 min following castration. Electroencephalogram recordings showed desynchronization for all treatments, consistent with increased arousal; yet the magnitude of desynchronization was greatest for 6-mo-old calves castrated by cut-and-clamp. Additionally, older calves in the cut-and-pull group showed greater desynchronization than younger calves in the same group. Based on the heart rate variability analysis, 6-mo-old calves in the control or cut-and-pull castration groups showed greater sympathetic tone than younger calves in the same treatment groups. Overall, younger calves showed lower electrodermal activity than older calves. Regardless of treatment, concentrations of cortisol and plasma

Received October 16, 2012.

Accepted April 4, 2013.

${ }^{1}$ Corresponding author: lucianab@vt.edu substance $\mathrm{P}$ were greater in 6-mo-old calves relative to their younger counterparts, indicating a more robust response to all treatments in older calves. In summary, neurohormonal and electroencephalographic stress responses of calves to castration were age-specific. Castration by cut-and-clamp showed the most pronounced stress response in 6-mo-old calves. These findings provide evidence that support welfare policies recommending castration at an early age and the use of analgesic compounds at the time of surgical castration especially in older calves. However, the potential long-term negative consequences of early untreated pain must be considered and warrant further investigation.

Key words: calf, castration, electroencephalogram, pain

\section{INTRODUCTION}

Castration is a common husbandry procedure used to decrease aggressive behavior, prevent unwanted matings, and modify carcass characteristics in cattle (Stafford, 2007). Currently, in the United States, less than $20 \%$ of producers provide pain relief at the time of castration (Coetzee et al., 2010). Consequently, castration without analgesia is considered standard industry practice in the United States at present. As the public's concern for food animal welfare increases, objective and noninvasive approaches of pain measurement are critical to assist in the development of science-based animal welfare policies. Unlike in Europe, currently no analgesic compounds have been approved for the alleviation of pain in food animals in the United States (AVMA, 2012). In accordance with United States Food and Drug Administration Guidance Document 123, validated methods of pain assessment must be used to prove that a pharmaceutical is efficacious before this can be labeled as an analgesic (FDA, 2006). This 
study was designed to assess the physiological response of calves of different ages to surgical and nonsurgical castration-induced pain by measuring their electroencephalogram, heart rate variability, infrared thermography, electrodermal activity, and plasma concentrations of cortisol and substance P.

The electroencephalogram (EEG) records the electrical activity of the cerebral cortical neurons which are believed to play a role in pain perception (Johnson, 2007). Activity is measured by 4 bands, namely low-frequency $\delta$ and $\theta$ and high-frequency $\alpha$ and $\beta$. In general terms, a typical EEG response to pain involves a decrease in total power, an increase in $95 \%$ spectral edge (the 95th percentile of the power spectrum), and an increase in median frequency (the statistical median of the power spectrum; Murrell and Johnson, 2006). This response is attributed to a decrease in low-frequency activity and an increase in high-frequency activity. This phenomenon is termed desynchronization and has been associated with increased arousal (Murrell and Johnson, 2006). A study performed in cattle during castration showed an association between EEG responses and cortisol concentrations, thereby suggesting that EEG may be useful in assessing increases in brain electrical activity associated with pain (Bergamasco et al., 2011).

Heart rate variability has also been used to measure stress in animals (von Borell et al., 2007). Heart rate variability assesses the function of the autonomic nervous system, especially the balance between sympathetic and vagal tone (Saul, 1990; von Borell et al., 2007). Some common variables assessed in heart rate variability analysis include mean heart rate, lowfrequency power, high-frequency power, low frequency to high frequency ratio, and number of successive R-R interval differences greater than $50 \mathrm{~ms}$ (NN50). A study on the effects of castration showed an increase in heart rate for calves castrated with and without local anesthetic, but no change for calves in the control groups (Stewart et al., 2010a). This study also found a decreased low frequency to high frequency ratio, indicative of increased vagal tone (Stewart et al., 2010a). This increase in parasympathetic activity may be associated with the deep visceral pain likely experienced when the spermatic cords are torn (Stewart et al., 2010a).

Infrared thermography is a technique used to measure the temperature of body areas. Ocular temperature has been shown to respond to castration-induced pain in a stimulus-dependent manner, suggesting it may be a useful tool for pain measurement (Stewart et al., 2010a). Electrodermal activity is the measurable change in skin electrical conductance in response to sympathetic stimulation (Critchley, 2005). Electrodermal activity is considered to represent brain stem reticular activation, and therefore may indicate the complex modalities of behavior and emotions in animals (Sequeira et al., 2009).

Pain causes activation of the hypothalamo-pituitaryadrenal axis, which is the neuroendocrine stress pathway (Cardo et al., 2011). The activity of this pathway can be measured by its end product, cortisol (Kent et al., 1993). Stressful situations augment the physiological secretion of cortisol and cause episodic peaks in concentrations, making it a useful stress indicator (Minton, 1994; Grandin, 1997; Bosch et al., 2009). Substance P has been described as a modulator of nociception, and has also been involved with transmission of painful stimuli to the central nervous system (DeVane, 2001). Previous studies have reported elevated substance P concentrations in calves following castration and dehorning (Coetzee et al., 2008, 2012).

In the present study, we examined physiological indicators of stress and pain induced by 1 of 2 surgical castration methods or a nonsurgical castration method applied to either young ( $\leq 8$-wk-old) or older $(\geq 6$-moold) calves. To our knowledge, no reports using EEG to measure pain response in calves of different age groups subjected to surgical and nonsurgical castration have been published. The aims of the present study were (1) to compare the physiological response to pain induced by surgical and nonsurgical (band) castration in calves and (2) to elucidate age-related differences in pain response of calves subjected to different castration methods.

\section{MATERIALS AND METHODS}

\section{Animals and Housing}

Forty Holstein bull calves aged approximately $8 \mathrm{wk}$ (30-60 kg on arrival) and 40 Holstein bull calves aged approximately $6 \mathrm{mo}(110-200 \mathrm{~kg}$ on arrival) were enrolled in the study. Eight-week-old calves arrived from Gill, CO on May 24, 2011. Six-month-old calves arrived from Conway Springs, KS on June 1, 2011. Processing procedures occurred $1 \mathrm{~d}$ after arrival. All calves received a single subcutaneous dose of the antibiotic oxytetracycline at $300 \mathrm{mg} / \mathrm{mL}$ (Noromycin $300 \mathrm{LA}$, Norbrook Inc., Lenexa, KS), a single subcutaneous dose of an 8-way clostridial vaccine (Covexin 8, Intervet/ Schering-Plough Animal Health, Summit, NJ), and a single subcutaneous dose of a bovine rhinopneumonitis vaccine (Bovi-Shield GOLD 5, Pfizer Animal Health, New York, NY) to prevent these common bovine diseases. A topical pour-on comprised of $5 \%$ permethrin and $5 \%$ piperonyl butoxide (Ultra Boss Pour-On Insecticide, Intervet/Schering-Plough Animal Health) was applied to all calves upon arrival and repeated as needed for fly control. Six-week-old calves were given 
$14 \mathrm{~d}$ for acclimation (calves were 8-wk-old at the time of treatment) and 6-mo-old calves were given $6 \mathrm{~d}$ for acclimation before study commencement. During acclimation, calves were individually restrained in the chute daily for $30 \mathrm{~min}$. Calves were weighed on arrival, at treatment, and $4 \mathrm{~d}$ postprocedure on an in-chute scale (Smartscale 500 USA, Gallagher Group Ltd., Hamilton, New Zealand). Weights at arrival were later used in the randomization process.

Eight-week-old calves were fed daily approximately at 0500 and $1700 \mathrm{~h}$. Each feeding consisted of $340 \mathrm{~g}$ of unmedicated milk replacer powder (Land O'Lakes Instant Amplifier Max, Land O'Lakes Inc., Shoreview, MN) mixed with $2.18 \mathrm{~L}$ of water in calf bottles. In addition, all calves were fed $0.68 \mathrm{~kg} / \mathrm{d}$ of a calf starter diet composed of rolled corn, soybean hulls, dried distillers grains, and soybean meal. This diet satisfied the requirements set forth by the NRC (NRC, 2012). Average daily gain from arrival through $4 \mathrm{~d}$ post-treatment was $0.25 \mathrm{~kg} / \mathrm{d}$ in this age group. Water was offered in buckets ad libitum. Calves were individually housed in 2 identical barns composed of twenty $1.5 \times 1.5$-m stalls with concrete floors, per industry standard with onehalf of each stall shaded by a tin roof. Four 8-wk-old animals were excluded from the study due to illness.

Six-month-old calves were fed, at $1300 \mathrm{~h}$ each day, approximately $10 \mathrm{~kg} / \mathrm{cow}$ of a growth diet composed of brome hay, dried distillers grains with solids, steepmonocalcium phosphate, soybean hulls, and dry-rolled corn. This diet satisfied the requirements set forth by the NRC (NRC, 2012). Average daily gain from arrival through $4 \mathrm{~d}$ post-treatment was $1.84 \mathrm{~kg} / \mathrm{d}$ in this age group. Water was offered ad libitum via an automatic waterer. Calves were housed in identical $4.3 \times 8.5-\mathrm{m}$ pens with concrete floors in groups of 4 with one-half of each pen shaded by mesh shade cloth.

This protocol (housing and castration procedures) was approved by the Institutional Animal Care and Use Committee (IACUC) at Kansas State University (Protocol \#2831) and followed the guidelines outlined in chapter 6 of the Guidelines for the Care and Use of Agricultural Animals in Research and Teaching (FASS, 2010). These guidelines state that injection of local anesthetic into the spermatic cords may be useful in surgical castration performed on calves greater than $230 \mathrm{~kg}$, but it has not been shown to improve postprocedural production (Ting et al., 2003; Wildman et al., 2006; Rust et al., 2007). In addition, the guidelines state that anesthesia shows no apparent benefit for banding and other bloodless methods of castration (Chase et al., 1995). All calves were housed at the Kansas State University Beef Cattle Research Center, Manhattan, KS. Calves were continuously monitored for pain for $8 \mathrm{~h}$ following surgery, then twice daily for $7 \mathrm{~d}$. Parameters monitored included attitude, gait and posture, appetite, lying, and scrotal swelling. Intervention was deemed necessary when calves exhibited obvious ataxia, hunching, dehydration, inflammation with major drainage of the scrotum, and no interest in food. Rescue analgesia (flunixin meglumine, $2.2 \mathrm{mg} / \mathrm{kg}$ IV BID) was available for calves showing these signs. This monitoring and analgesia protocol was approved as part of the Animal Monitoring Plan in the IACUC protocol.

\section{Group Assignment and Randomization Procedures}

At arrival, calves were blocked by age and weight and randomly assigned to treatment groups. The groups were control (CONT; $\mathrm{n}=20$ ), banding (BAND; $\mathrm{n}$ $=18$ ), cut-and-clamp (CLAMP; $\mathrm{n}=20)$, or cut-andpull (PULL; $\mathrm{n}=18$ ). All treatments took place in a hydraulic, double-alley squeeze chute with a belly bar placed underneath the calf for support and to prevent collapse (Figure 1; Daniels Manufacturing Co., Ainsworth, NE). Calves were held for $1 \mathrm{~h}$ in a holding pen before the start of each study session for acclimation. The CONT treatment consisted of scrotal manipulation only with no pulling. The BAND treatment consisted of scrotal manipulation followed by the application of a latex band around the scrotum using an elastrator tool. Younger calves were castrated using a simple elastrator with latex bands and older calves were castrated using a Callicrate tool with ratchet loops (No-Bull Enterprises LLC, St. Francis, KS). The Callicrate tool allows the user to tighten the band around the scrotum with a ratcheting action to achieve ischemia in the testicles and scrotal tissues. The CLAMP treatment consisted of scrotal manipulation followed by a scrotal incision with a scalpel and clamping of the spermatic cords with an emasculator. Lastly, the PULL treatment consisted of scrotal manipulation followed by a scrotal incision with a scalpel and pulling of the testicles until rupture of the spermatic cords. All of these castration methods are common practice in the United States (Figure 2). Prior to castration, the scrotum was disinfected with an iodine solution (Triadine Povidone-Iodine USP Prep Solution, Triad Disposables Inc., Brookfield, WI) and any tools were thoroughly cleaned with $70 \%$ isopropyl alcohol (Isopropyl Rubbing Alcohol 70\%, Vi-Jon Inc., St. Louis, MO). For consistency, all treatments were performed by the same experienced operator. A total of 8 calves were processed on each study day such that all treatment and age group combinations (arranged in random order) were represented in a given day.

Jugular catheters (14 gauge $\times 140 \mathrm{~mm}$; Abbocath- $\mathrm{T}$ $(305 \mathrm{~mL} / \mathrm{min})$, Abbott Ireland, Sligo, Republic of Ireland) with $76-\mathrm{cm}$ extension sets (Extension Set with Slip Luer Slide Clamp, Abbott Ireland) were inserted 


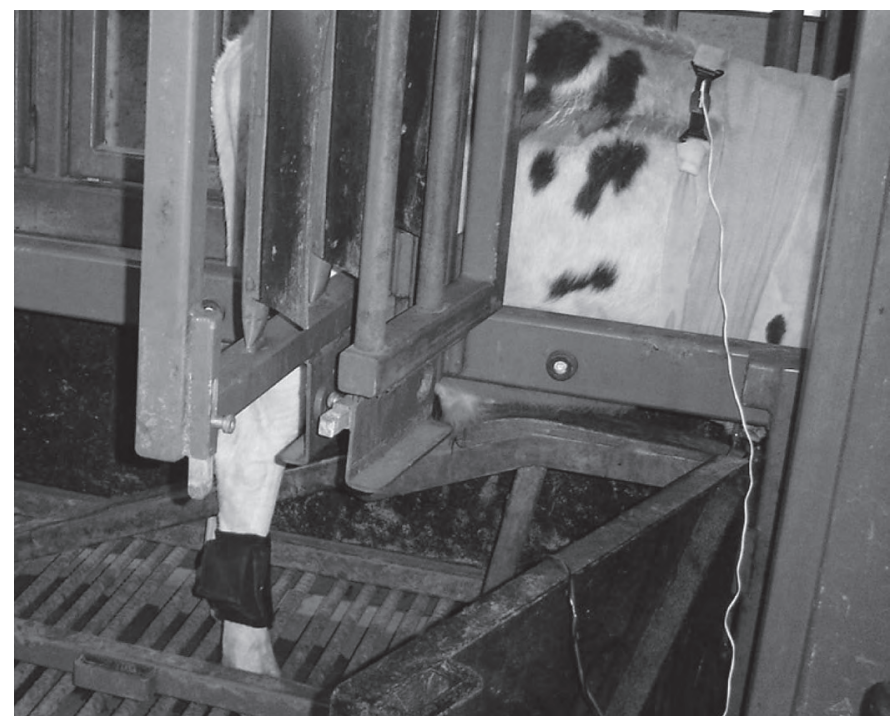

Figure 1. Photograph of the belly bar used to support calves and to prevent collapse while in the chute.

on the left side of the neck $1 \mathrm{~d}$ before each calf's assigned study day. Before catheter insertion, the neck was shaved and cleaned with iodine and $70 \%$ isopropyl alcohol (Isopropyl Rubbing Alcohol 70\%, Vi-Jon Inc.). Local anesthesia was provided $(0.5 \mathrm{~mL}$ of Lidocaine $\mathrm{HCl}$ $2 \%$ at $20 \mathrm{mg} / \mathrm{mL}$, Hospira Inc., Lake Forest, IL) followed by a stab incision with a \#22 scalpel blade and catheter insertion. The stab incision penetrated just through the skin and catheters were held in place with

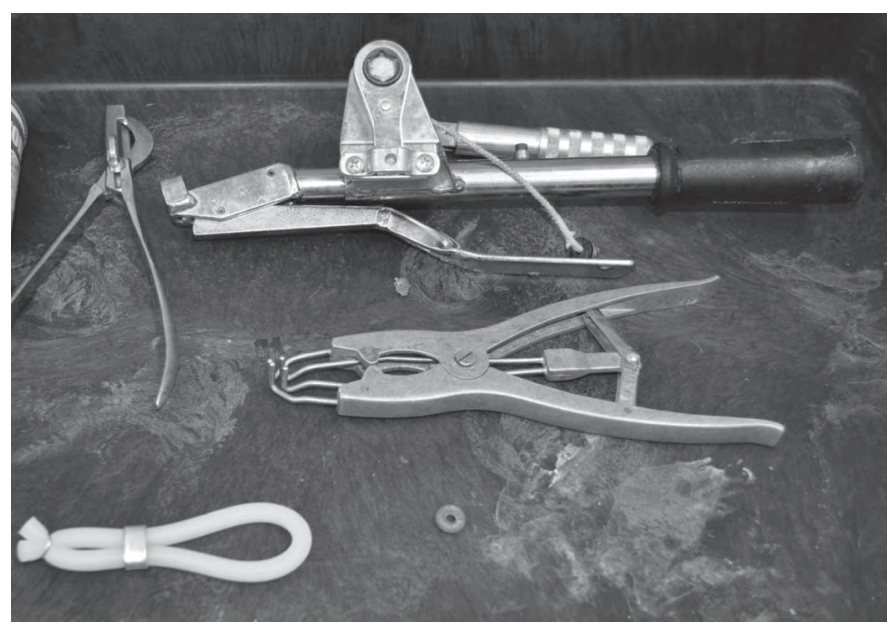

Figure 2. Photograph of all castration implements used during the study. Pictured on the left is the emasculator, pictured on the top is the Callicrate banding tool (No-Bull Enterprises LLC, St. Francis, $\mathrm{KS}$ ), pictured in the middle is the elasticator banding tool, and pictured on the bottom are examples of the Callicrate band and the elasticator band. a single nylon suture. Catheters remained in place for approximately $24 \mathrm{~h}$.

\section{EEG Data Recording and Management}

During each experimental session, calves were restrained in the chute and electrodes were placed transcutaneously in a 12-channel montage (F3, F4, T3, C3, $\mathrm{Cz}, \mathrm{C} 4, \mathrm{~T} 4, \mathrm{P} 3, \mathrm{Pz}, \mathrm{P} 4, \mathrm{O} 1, \mathrm{O} 2$; odd number = left hemisphere, even number $=$ right hemisphere) to record EEG (Sandman Spyder, Tyco Healthcare, Puritan Bennet Ltd., Kanata, Canada; Figure 3) as previously described (Bergamasco et al., 2011).

Electroencephalogram recording started when electrode placement was completed, approximately 10 min after calves were restrained. The total recording time was $30 \mathrm{~min}$ for each calf, including calibration and the initial impedance check. The EEG data were then stored in the acquisition station for later processing. The timeline of the EEG recording included (1) baseline (8-10 min before treatment), (2) immediate recovery (0-5 min post-treatment), (3) middle recovery (5-10 min post-treatment), and (4) late recovery

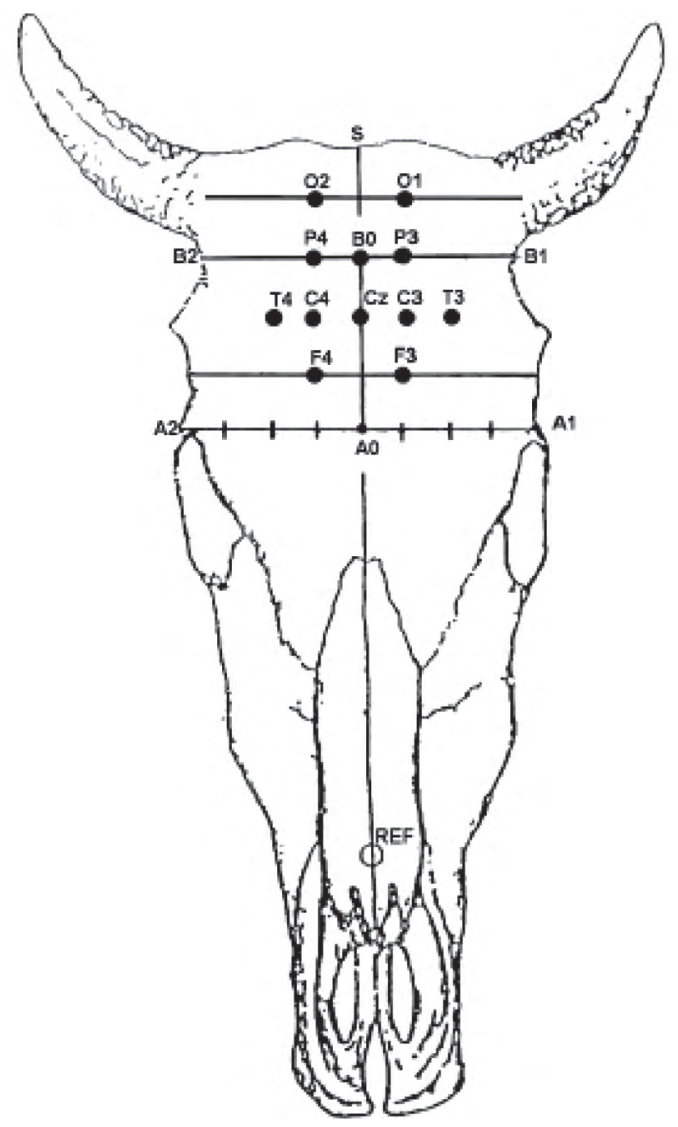

Figure 3. Map of electroencephalogram electrode placement. 
(10-20 min post-treatment). Visual inspection of the EEG was performed to evaluate background activity by an experienced operator blind to treatment and age classification. Special emphasis was given to artifact detection and elimination, as artifacts strongly affect the frequency analysis of the EEG. Ocular movements, cardiovascular and muscular activity, physiological rhythmic movements, or recording environment artifacts were noted and manually rejected.

Spectral analysis of the EEG was performed using fast Fourier transformation (Sandman Spyder, Tyco Healthcare, Puritan Bennet Ltd.). For all calves, at least 30 replications of 2 -s long artifact-free epochs were selected from each EEG time point. Fast Fourier transformation was calculated and averaged for each channel. The spectral bands of $\delta(0.50-4.00 \mathrm{~Hz}), \theta$ $(4.10-8.00 \mathrm{~Hz}), \alpha(8.10-12.00 \mathrm{~Hz})$, and $\beta(12.10-30.00$ $\mathrm{Hz}$ ) were calculated and expressed as absolute power $\left(\mu \mathrm{V}^{2}\right)$ and relative power (\%). Total power $\left(\mu \mathrm{V}^{2}\right)$ of the entire spectrum $(0.5-30.0 \mathrm{~Hz})$ was also calculated.

\section{Heart Rate Variability}

Heart rate and heart rate variability were continuously recorded with commercially-available heart rate monitors (Polar Equine, Polar Electro Oy, Kempele, Finland), which consisted of a transmitter and receiver. Monitors were fitted 5 min before calves were placed into the chute (before the start of data collection) and removed at the end of the sampling period. The left and right sides of the thorax over the cardiac silhouette were shaved and ultrasound gel (Ultrasound Gel, Medline Industries Inc., Mundelein, IL) was applied to facilitate electrode contact with the thorax. Transmitter and receiver were fixed to the animal using an elastic belt and cohesive flexible bandages (Fisherbrand Cohesive Flexible Bandage, Fisher Scientific, Pittsburgh, PA). The timeline of heart rate variability analysis included (1) baseline ( 5 min pretreatment), (2) immediate recovery (0-5 min post-treatment), (3) middle recovery (5-10 min post-treatment), and (4) late recovery (10-15 min post-treatment). Time periods of equal length $(5 \mathrm{~min})$ were analyzed to fulfill recommendations for analysis of heart rate variability (Task Force, 1996). Variables analyzed included mean heart rate, NN50, normalized low-frequency power, normalized high-frequency power, and low frequency to high frequency ratio. These data were then evaluated using research grade heart rate variability analysis software (Kubios Heart Rate Variability version 2.0, Biosignal Analysis and Medical Imaging Group, Joensuu, Finland). The detrending method used was smoothing priors $(\lambda=500)$ and the frequency bands were specified as follows: very low frequency, 0.003 to $0.04 \mathrm{~Hz}$; low frequency, 0.04 to $0.3 \mathrm{~Hz}$; and high frequency, 0.3 to $0.8 \mathrm{~Hz}$. The interpolation rate was $4 \mathrm{~Hz}$ and the frequency domain was made up of 256 points $/ \mathrm{Hz}$. The default value for window width of $256 \mathrm{~s}$ was used according to Welch's periodogram method (fast Fourier transformation spectrum) with the default overlap of $50 \%$ (corresponding to $128 \mathrm{~s}$ ). In Welch's periodogram method the heart rate variability sample is divided into overlapping segments. The spectrum is then obtained by averaging the spectra of these segments. This method decreases the variance of the fast Fourier transformation spectrum.

\section{Infrared Thermography}

Changes in ocular temperature were measured using a commercially-available infrared inspection system (Thermacam S65, FLIR Systems, Wilsonville, OR). Pictures were taken at 180,120 , and $60 \mathrm{~s}$ before treatment, at the time of treatment (0 s), and 60,90, 120, 150 , and $180 \mathrm{~s}$ after treatment. A previous study noted most eye temperature changes occurred 5 min before and 5 min after castration (Stewart et al., 2010b). Due to technical issues precluding the use of this amount of data, our samples were analyzed for $3 \mathrm{~min}$ before and 3 min after castration. Images were analyzed for changes in temperature using research grade software (Thermacam Researcher Pro 2.8 SR-1, FLIR Systems) by selecting a circular area around the eye and calculating the maximum eye temperature, minimum eye temperature, and average eye temperature $\left({ }^{\circ} \mathrm{C}\right)$. Ambient temperature and relative humidity in the barn were recorded and entered into the infrared camera to ensure calibration for atmospheric conditions.

\section{Electrodermal Activity}

Electrodermal activity was measured using a commercially available pain device (Pain Gauge, PHIS Inc., Dublin, OH; Figure 4). Possible values recorded by this device ranged from 0 (calm or no pain) to 9.9 (tense or severe pain). Electrodes were placed across the nasal planum and measurements taken $10 \mathrm{~min}$ before treatment, 5 min before treatment, at treatment, 5 min after treatment, and 10 min after treatment as previously described (Kotschwar et al., 2009; Baldridge et al., 2011).

\section{Cortisol}

Blood samples ( $3 \mathrm{~mL})$ were drawn at baseline, 5,10 , $20,30,40,50,60,120,240,480$, and 5,760 min relative to treatment for cortisol analysis. Blood was collected from catheters into serum clot activator tubes (Vacuette $6 \mathrm{~mL} \mathrm{Z}$ Tubes, Greiner Bio-One, Kremsmünster, Austria) and was centrifuged at $1,500 \times g$ for $10 \mathrm{~min}$ 


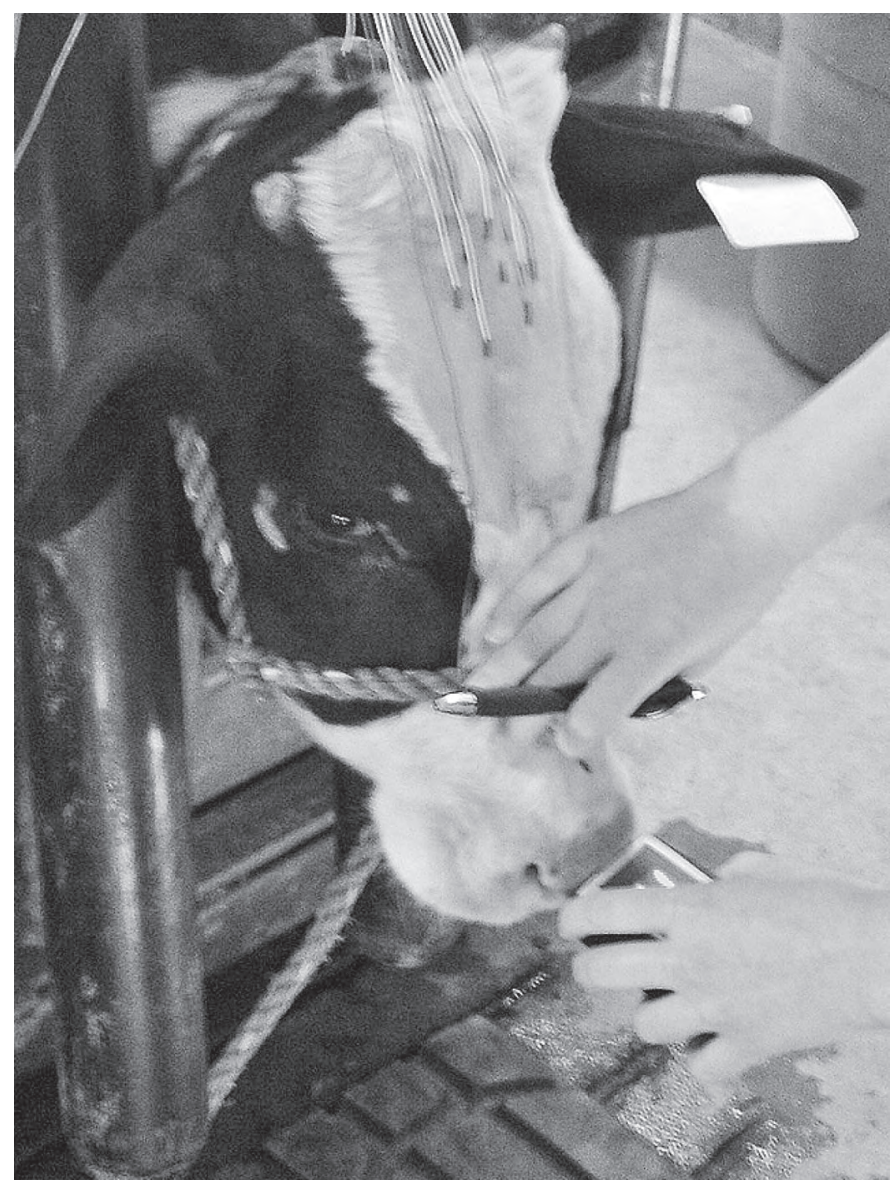

Figure 4. Photograph of electrodermal activity data collection.

within 30 min of collection. The serum was transferred to two 2-mL cryogenic vials (Fisherbrand Cryogenic Storage Vials, Fisher Scientific) and frozen at $-80^{\circ} \mathrm{C}$ before analysis. Serum cortisol concentrations were determined as previously described (Coetzee et al., 2007). This method has been cross-validated between serum and plasma in the Kansas State University Veterinary Diagnostic Laboratory (Baldridge et al., 2011). In addition, the area under the plasma concentration curve (AUC), maximum cortisol concentration (Cmax), and time to maximum cortisol concentration (Tmax) were calculated.

\section{Substance $P$}

Blood samples $(3 \mathrm{~mL})$ were drawn at baseline, 60 , 120, 240, 480, and 5,760 min relative to castration for substance $\mathrm{P}$ analysis. Blood was collected from catheters into EDTA K3 tubes (Vacuette 6mL K3E Tubes, Greiner Bio-One). A 20-m $M$ solution of benzamidine was prepared in water and $300 \mu \mathrm{L}$ was added to each EDTA K3 tube for a final concentration of $1 \mathrm{mM}$ of benzamidine in whole blood to serve as a protease inhibitor. These tubes were centrifuged at $1,500 \times g$ for $10 \mathrm{~min}$. The plasma transferred to two $2-\mathrm{mL}$ cryogenic vials and stored at $-80^{\circ} \mathrm{C}$ until analysis. Samples were analyzed for substance $\mathrm{P}$ concentrations using a validated analytical method and in the same laboratory as previously described (Coetzee et al., 2008; Coetzee et al., 2012).

\section{Statistical Analysis}

A general linear mixed model was fitted to each of the following response variables: EEG single frequency absolute power and relative power for each of the $\delta, \theta, \alpha$, and $\beta$ bands; EEG total power; mean heart rate; NN50; low frequency to high frequency ratio; maximum eye temperature; minimum eye temperature; average eye temperature; electrodermal activity; cortisol concentrations; cortisol Tmax; cortisol Cmax; cortisol AUC; and substance $\mathrm{P}$ concentrations. The following responses were log-transformed before analysis to stabilize variances and meet model assumptions. In particular, EEG single frequency absolute power for each of the bands and relative power for $\alpha, \beta$, and $\theta$ bands, EEG total power, low frequency to high frequency ratio, cortisol Tmax, and substance P concentrations were log-transformed, whereas $\delta$ band relative power was transformed by squaring (i.e., power of 2 ).

In turn, a generalized linear mixed model was fitted to each of the responses low-frequency power and highfrequency power assuming a $\beta$ distribution and using a logit link function to connect to the linear predictor. The linear predictor in the statistical models used for analysis included the fixed effects of treatment (CONT, BAND, CLAMP, or PULL), age group (8-wk-old or 6 -mo-old), and time relative to castration, as well as all 2- and 3-way interactions.

For all EEG responses (i.e., absolute power, relative power, and total power), a random effect of calf nested within age and treatment combination was specified to recognize potential correlations between repeated observations on a given calf and also identify the calf as the appropriate experimental unit for the corresponding factors. In addition, the residual covariance structure for each calf measured at each time point was fitted using a spatial power structure to accommodate the spatial arrangement of EEG equipment. A blocking effect of pen was fitted as a random component when possible; however, for heart rate, NN50, low-frequency power, high-frequency power, low frequency to high frequency ratio, electrodermal activity, and cortisol concentration, the corresponding variance component estimate converged to zero, thus the effect of pen was removed from the model. For electrodermal activity, an 
additional random effect of animal by time-point combination was fitted to recognize unbalanced subsampling in the data collection process. For infrared thermography and substance $P$, the variance components for the random effects of pen nested within age group and also of pen crossed with treatment were included in the final model to recognize the appropriate experimental units for each of these factors.

Satterthwaite's method was used to estimate degrees of freedom and Kenward Roger's procedure was used for the corresponding adjustments in estimated standard errors. When general linear mixed models were fitted, assumptions were evaluated using externally studentized residuals; inference followed upon the indication that those assumptions were reasonably met. Data points that were considered to be subject to technical recording errors were excluded from analyses. Also, significant outliers detected using a Bonferronicorrected test on studentized residuals were excluded from analyses (heart rate and cortisol concentration). All statistical models were fitted using the GLIMMIX procedure of SAS (Version 9.2, SAS Institute, Cary, NC), implemented using Newton-Raphson with ridging as the optimization technique. Relevant pairwise comparisons were conducted using Bonferroni or Tukey-Kramer adjustments, as deemed appropriate in each case, to avoid inflation of Type I error rate due to multiple comparisons. A $P$-value of $P \leq 0.05$ was considered statistically significant, whereas a $P$-value of $P \leq 0.10$ was considered marginally significant.

\section{RESULTS}

\section{EEG}

For absolute power, a 2-way interaction between age and treatment was noted for the $\delta, \theta, \alpha$, and $\beta$ bands $(P=0.01, P=0.07, P=0.06$, and $P=0.07$, respectively). In particular, $\delta$ band absolute power was greater for 6-mo-old CONT calves relative to those castrated by CLAMP $(P=0.01$; Figure 5a), whereas castration by PULL and BAND showed intermediate $\delta$ band absolute power that was not significantly different from either group. In contrast, among 8-wk-old calves, $\delta$ band absolute power was greater for castration by PULL than CONT or CLAMP $(P=0.05$ and $P=0.05$, respectively; Figure 5a); castration of 8 -wk-old calves by BAND showed intermediate absolute power of the $\delta$ band and was not significantly different from any other treatment group. Also, younger calves castrated by PULL had greater absolute power for $\theta(P=0.03)$ and $\alpha(P=0.03)$ bands than those castrated by CLAMP (Figure 5b and 5c); whereas castration by CONT and BAND showed intermediate absolute power for both bands. For the $\beta$ band, castration of 8 -wk-old calves by PULL showed greater absolute power than castration by BAND $(P=0.02$; Figure $5 \mathrm{~d})$. In contrast, among 6-mo-old calves, no evidence for differences was observed between castration treatments for any of the $\theta$, $\alpha$, or $\beta$ frequency bands. Additionally, when castrated by PULL, 8-wk-old calves had greater absolute power of $\delta, \theta, \alpha$, and $\beta$ bands than their 6-mo-old counterparts $(P=0.004, P=0.002, P=0.001$, and $P=0.04$, respectively); these age-related differences were not apparent with other castration methods.

Regarding relative power, a 2-way interaction between age and treatment was also evident for $\delta$ and $\beta$ bands $(P=0.01$ and $P=0.05$, respectively; Figure $6)$. In particular, 6-mo-old calves in the CONT group had greater $\delta$-relative power $(P=0.004)$ and lower $\beta$-relative power $(P=0.03)$ than those castrated by CLAMP. In contrast, no significant differences between castration methods were noted for relative power in 8-wk-old calves. Additionally, in the CONT group, $\delta$-relative power was greater for 6 -mo-old than for 8 -wkold calves $(P=0.01)$.

On total power, evidence for a 2 -way interaction between age and treatment $(P=0.03$; Figure 7$)$ was also observed, whereby 6-mo-old calves in the CONT group showed greater total power than calves of the same age castrated by CLAMP $(P=0.05)$. In turn, among 8 -wkold calves, the PULL group showed greater total power than castration by CLAMP $(P=0.05)$ and CONT $(P=0.06)$. Moreover, age-specific differences in total power were apparent only when castration was conducted by PULL, whereby 8-wk-old calves had greater total power than 6 -mo-old calves $(P=0.004)$; no other castration method showed evidence for age difference in total power.

A time effect was also noted for several EEG results. Specifically, the absolute power of $\theta$ and $\alpha$ bands decreased significantly from baseline through late recovery $(P=0.0001)$ for all ages and treatments. In contrast, relative power of the $\delta$ band decreased from baseline through late recovery $(P<0.0001)$, whereas relative power of the $\theta$ and $\beta$ bands increased from baseline through late recovery for all ages and castration methods ( $P=0.0039$ and $P=0.02$, respectively). For relative power of the $\alpha$ band, power increased from baseline through middle recovery for all treatments and age groups $(P<0.02)$. Total power decreased after baseline and stayed low throughout the evaluation period for all ages and treatments $(P<0.0001)$.

\section{Heart Rate Variability}

For mean heart rate, we found evidence of a 2-way interaction between age and time $(P=0.01$; Figure 8$)$, 


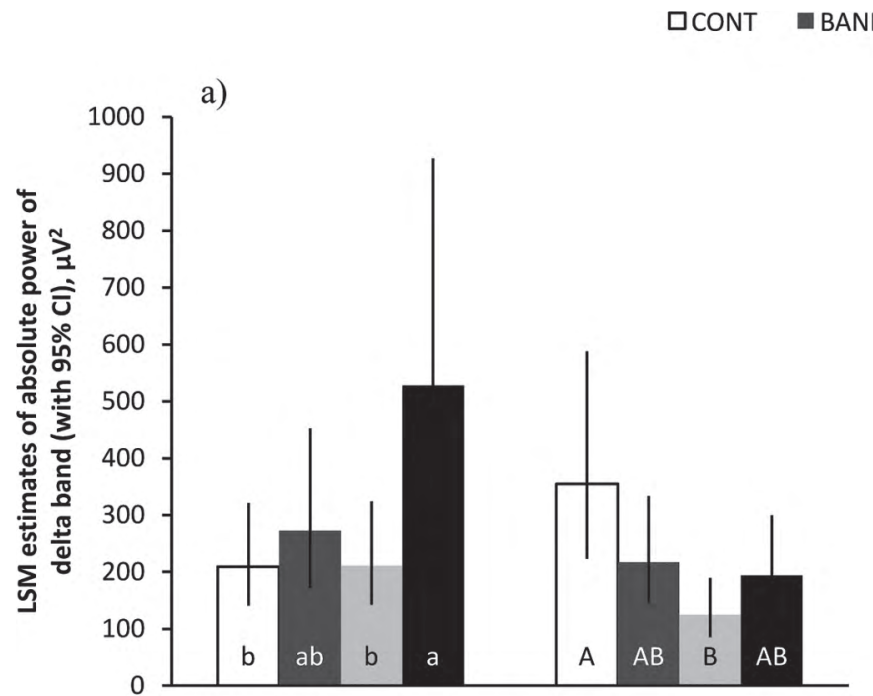

b)

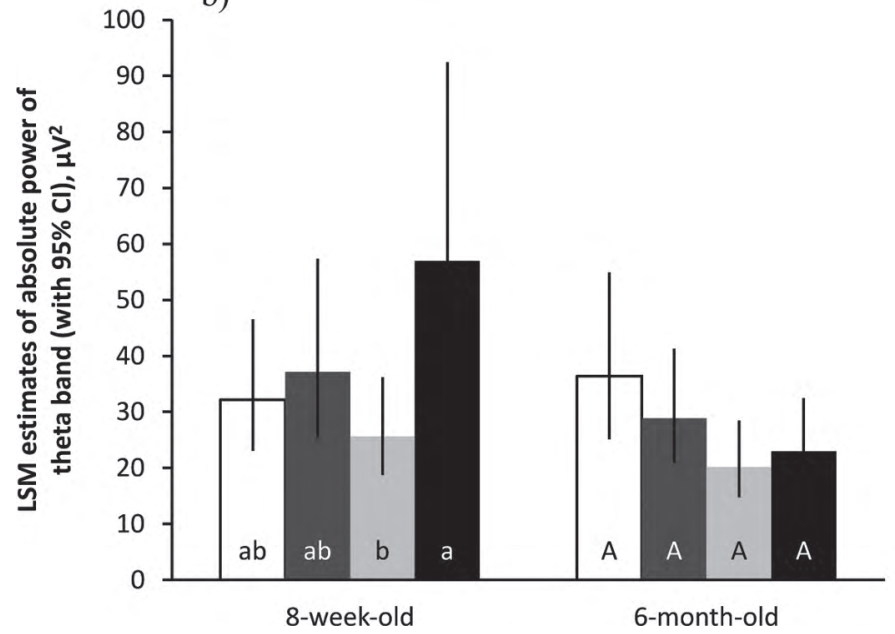

CLAMP $\quad$ PULL

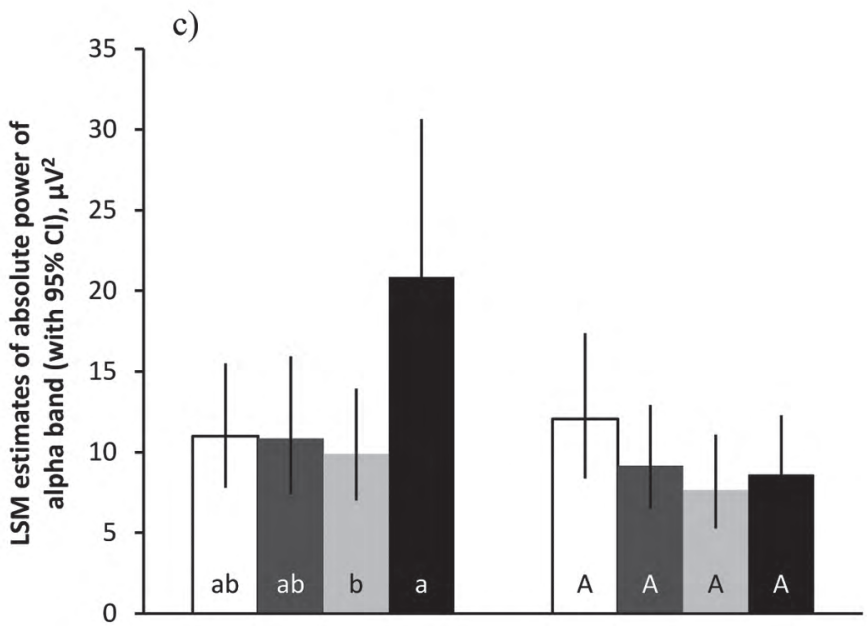

d)

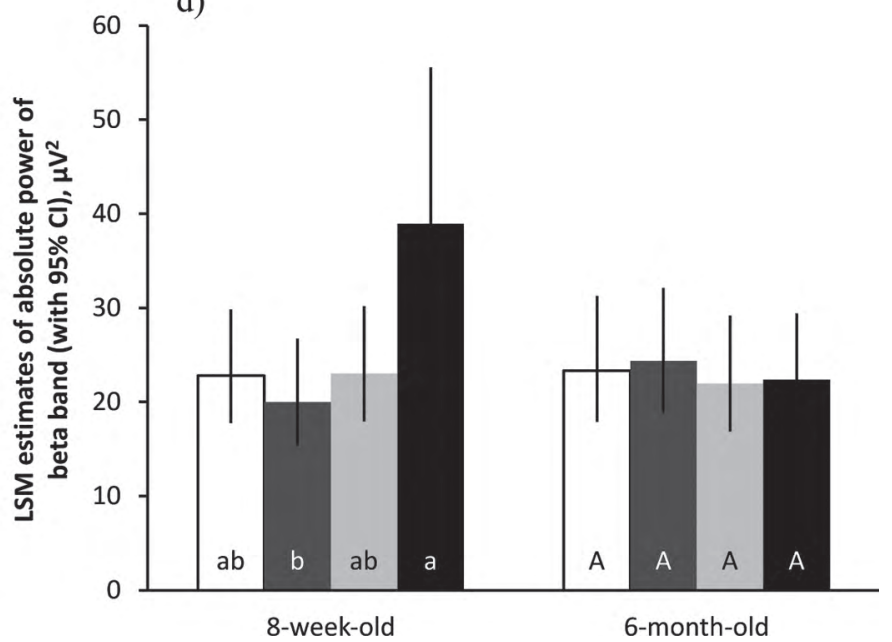

Figure 5. Least squares means estimates (and 95\% CI) for absolute power ( $\mu \mathrm{V}^{2}$ ) of the $\delta$ (a), $\theta$ (b), $\alpha$ (c), and $\beta$ bands (d) of 8 -wk-old and 6-mo-old calves subjected to control (CONT) or castration by banding (BAND), cut and clamp (CLAMP), or cut and pull (PULL) procedure. Uppercase letters (A, B) indicate significant differences between castration treatments for 6-mo-old animals; lowercase letters (a, b) indicate significant differences between castration treatments for 8 -wk-old animals $(P \leq 0.05)$.

but no significant effect of castration method was apparent. More specifically, regardless of castration method, younger calves experienced an increase in heart rate after castration through 10 to 20 min postcastration $(P=0.01)$; however, this increase was not apparent in older calves. Regarding NN50, a main effect of age was evident, whereby younger calves showed a greater NN50 than older calves $(P=0.03)$.

For low-frequency power, we found evidence for a 2 -way interaction between treatment and age $(P=$ $0.04)$, whereby 6 -mo-old calves in CONT $(P=0.02)$ or castrated by PULL $(P=0.01)$ showed greater lowfrequency power than 8-wk-old calves in the same treatment groups (Figure 9); no evidence for age differences in low frequency power was apparent among calves castrated by BAND or CLAMP. Results for high-frequency power showed evidence for a 2 -way interaction between treatment and age $(P=0.04)$. In particular, 6 -mo-old calves in the CONT $(P=0.02)$ or PULL $(P=0.01)$ groups showed lower high-frequency power compared with 8-wk-old animals in the same groups. Similarly, for low frequency to high frequency ratio, a 2-way interaction between treatment and age $(P=0.05)$ was noted, whereby 6-mo-old calves in the CONT $(P=$ $0.06)$ or PULL $(P=0.01)$ groups showed greater low frequency to high frequency ratio than younger calves undergoing the same treatments.

\section{Infrared Thermography}

Regarding average eye temperature, we found marginal evidence for a main effect of age $(P=0.06)$. Re- 


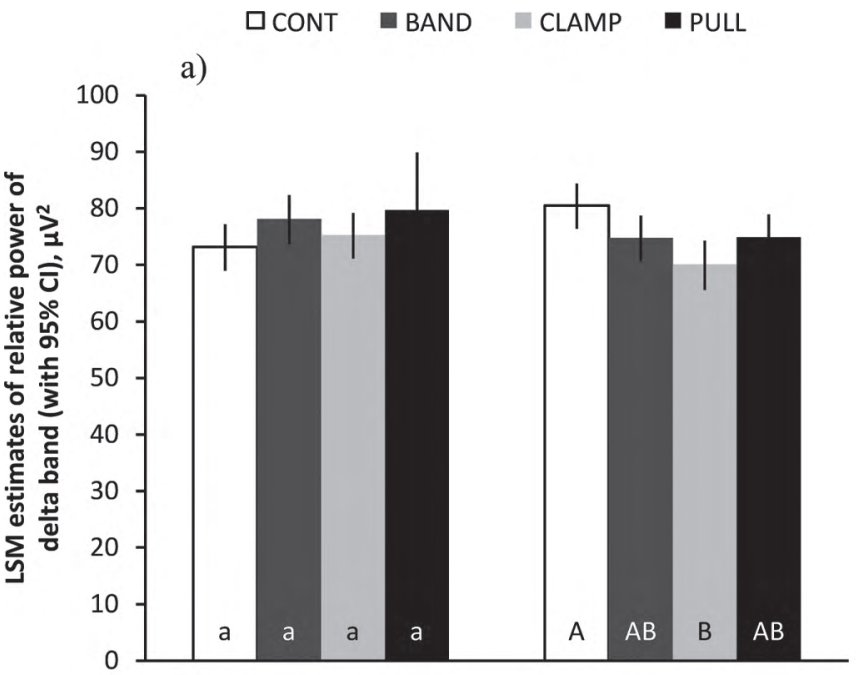

b)

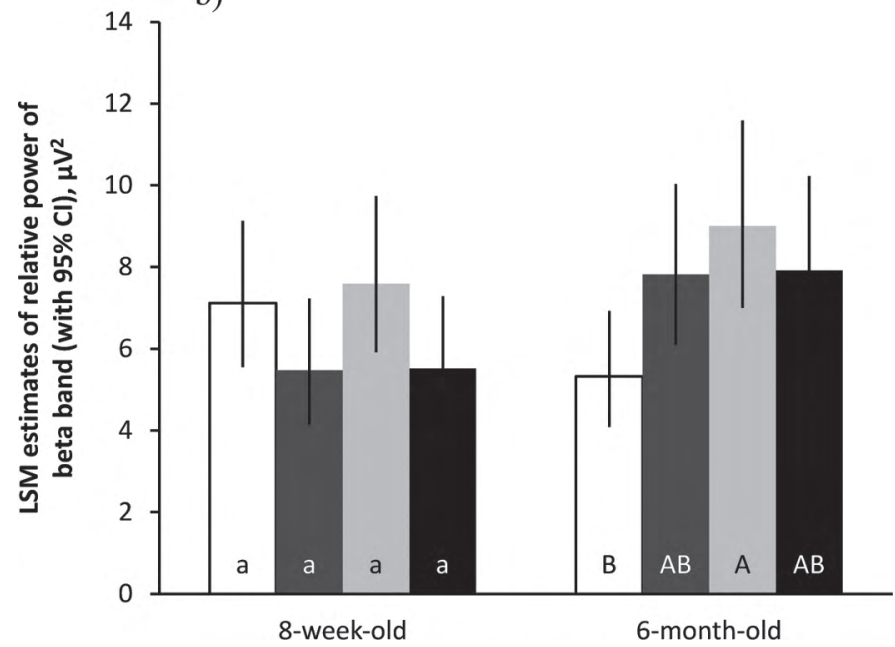

Figure 6. Least squares means estimates (and 95\% CI) for relative power (\%) of the $\delta(\mathrm{a})$ and $\beta$ (b) bands of 8-wk-old and 6-mo-old calves subjected to control (CONT) or castration by banding (BAND), cut and clamp (CLAMP), or cut and pull (PULL) procedure. Uppercase letters $(\mathrm{A}, \mathrm{B})$ indicate significant differences between castration treatments in 6-mo-old calves; lowercase letters $(\mathrm{a}, \mathrm{b})$ indicate significant differences between castration treatments for 8 -wk-old animals $(P \leq$ $0.05)$.

gardless of castration method, 6-mo-old calves showed marginally greater average eye temperature than 8 -wkold calves over the period of chute restraint.

For minimum eye temperature, marginal evidence for a 2-way interaction between age and time $(P=0.08)$ was noted. More specifically, 8-wk-old calves showed evidence for an increase in minimum eye temperature from $-180 \mathrm{~s}$ to treatment (time 0 ) and later, regardless of treatment. In contrast, 6-mo-old calves showed no evidence of changes in minimum eye temperature over time for any castration method.

No evidence was found for differences in maximum eye temperature between treatment and age groups.

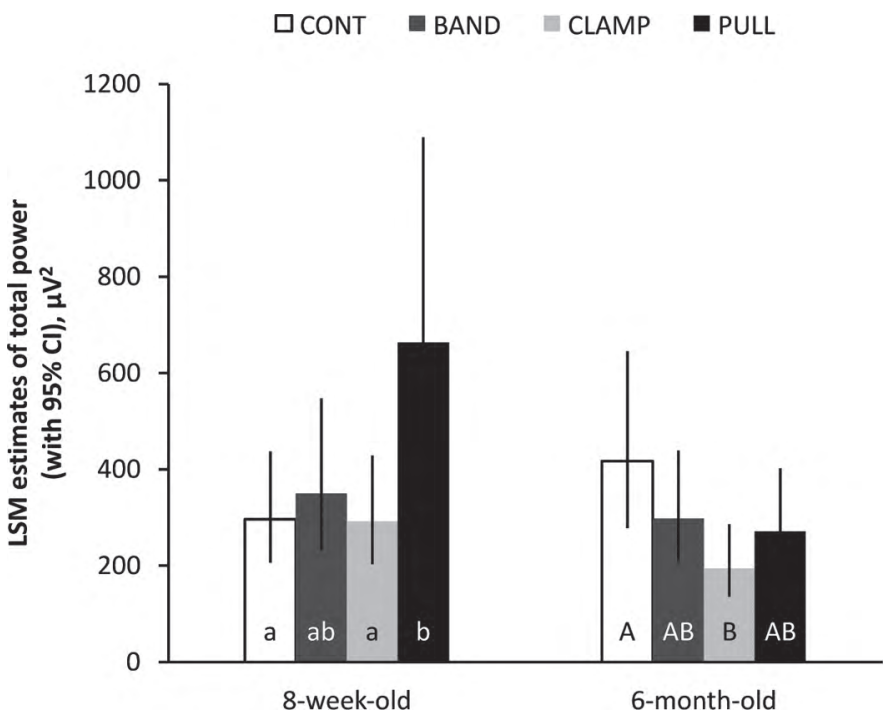

Figure 7. Least squares means estimates (and 95\% CI) for total power $\left(\mu \mathrm{V}^{2}\right)$ of 8-wk-old and 6-mo-old calves subjected to control (CONT) or castration by banding (BAND), cut and clamp (CLAMP), or cut and pull (PULL) procedure. Uppercase letters (A, B) indicate differences between castration treatments in 6-mo-old animals; lowercase letters $(\mathrm{a}, \mathrm{b})$ indicate significant differences between castration treatments in 8 -wk-old animals $(P \leq 0.05)$.

However, this response showed evidence for a time effect $(P<0.0001)$ whereby, regardless of age and castration method, an increase in maximum eye temperature was apparent from before treatment to after treatment with a small, transient peak at the time of castration.

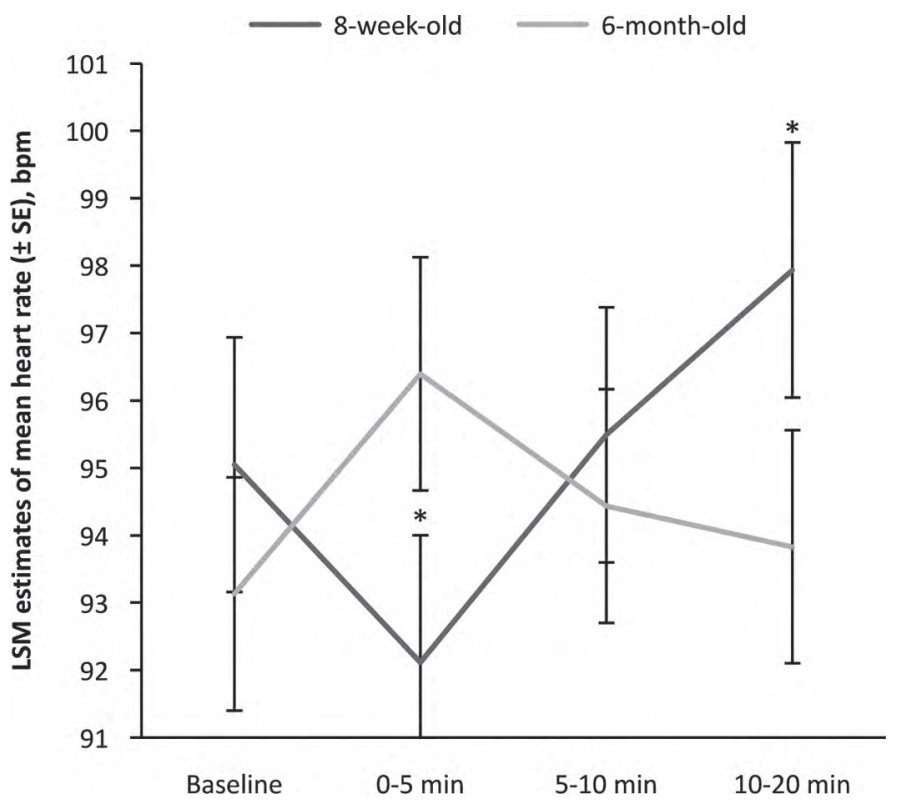

Figure 8. Least squares means estimates (and SE) for mean heart rate (bpm) of 8-wk-old and 6-mo-old calves. An asterisk ${ }^{*}$ ) indicates significant difference between time points after castration within a given age group $(P \leq 0.05)$. 


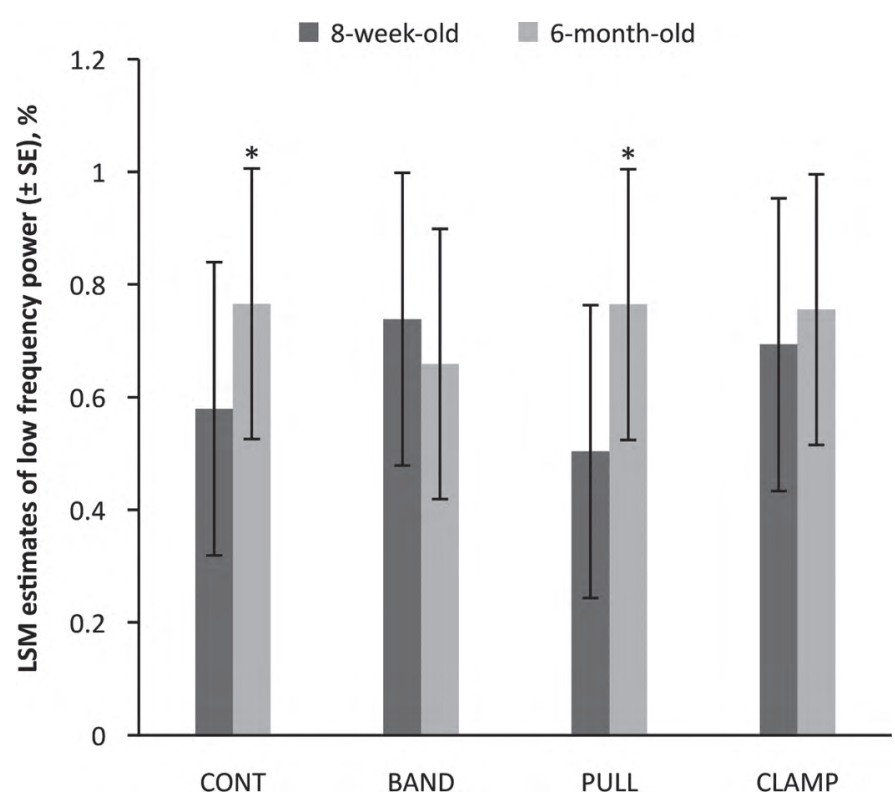

Figure 9. Least squares means estimates (and SE) for heart rate variability normalized low frequency power (\%) of 8-wk-old and 6-mo-old calves subjected to control (CONT) or castration by banding (BAND), cut and clamp (CLAMP), or cut and pull (PULL) procedure. An asterisk $(*)$ indicates significant difference between age groups within a given castration treatment $(P \leq 0.05)$.

\section{Electrodermal Activity}

No evidence for any effect of castration on electrodermal activity was apparent, but a 2 -way interaction between age and time was evident $(P=0.02)$. Regardless of castration method, 8-wk-old calves showed lower electrodermal activity at treatment and through 10 min post-treatment than older calves $(P=0.03, P=$ 0.0003 , and $P=0.01$, respectively; Figure 10).

\section{Cortisol}

For cortisol concentrations in plasma, we noted evidence for a 2-way interaction between age and time $(P$ $<0.001)$. We also found evidence for a main effect of age on cortisol AUC $(P=0.002)$ and on Cmax $(P=$ 0.001 ) such that both were increased in 6 -mo-old calves relative to their 8-wk-old counterparts, regardless of castration method (Table 1). Finally, for cortisol Tmax, a 2-way interaction between age and treatment $(P=$ 0.04) was noted (Table 1). Among controls, 6-mo-old calves showed a shorter Tmax compared with 8-wk-old calves $(P=0.02)$; however, no significant age differences were apparent for the remaining castration methods. Furthermore, for 6-mo-old calves, castration by BAND or CLAMP induced a longer Tmax than CONT $(P=$ 0.02 and $P=0.02$, respectively). No treatment differences were evident in 8-wk-old calves.

\section{Substance $P$}

Concentrations of substance $\mathrm{P}$ differed by age $(P=$ 0.01 ), whereby 6 -mo-old calves had greater concentrations of substance $\mathrm{P}$ relative to 8-wk-old calves regardless of castration method (Figure 11).

\section{DISCUSSION}

The primary objective of this study was to assess the physiological response to pain in calves, using castration as a model to elucidate the differences in pain response between age groups and castration methods. Rescue analgesia was not deemed necessary for any animals during the study using criteria approved by the IACUC.

\section{Electroencephalogram}

A desynchronization pattern in the EEG typically involves a decrease in total power, produced by a decrease in low-frequency activity ( $\delta$ and $\theta$ bands) and an increase in high-frequency activity ( $\alpha$ and $\beta$ bands) (Murrell and Johnson, 2006). This phenomenon has been associated with an increased level of arousal, and is considered indicative of an increased level of pain (Murrell and Johnson, 2006). Frequency activity is more often reported in terms of relative power than absolute power, as relative power is intended to standardize

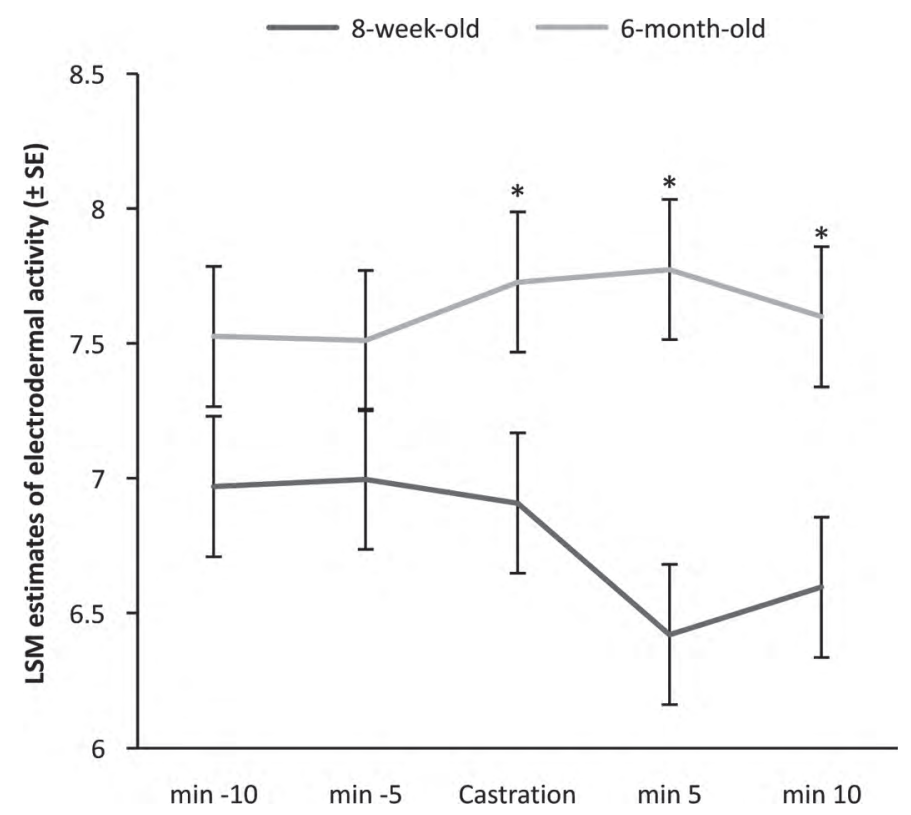

Figure 10. Least squares means estimates (and SE) for electrodermal activity of 8-wk-old and 6-mo-old calves. An asterisk (*) indicates significant difference between age groups within a given time interval after castration $(P \leq 0.05)$. 
Table 1. Least squares means estimates (and SE or 95\% CI) for area under the plasma cortisol curve (AUC), minimum and maximum cortisol concentration (Cmax), and time to maximum cortisol concentration (Tmax)

\begin{tabular}{llll}
\hline Pharmacokinetics & Treatment $^{1}$ & 8-wk-old cows & 6-mo-old cows \\
\hline AUC, nmol/L & CONT & $106,753.33(72,732.07,140,774.58)^{\mathrm{A}}$ & $144,967.49(84,736.67,205,198.31)^{\mathrm{B}}$ \\
& BAND & $69,681.72(31,644.80,107,718.64)^{\mathrm{A}}$ & $156,430.73(99,221.98,213,639.47)^{\mathrm{B}}$ \\
& PULL & $102,308.16(64,271.24,140,345.07)^{\mathrm{A}}$ & $182,457.68(125,248.93,239,666.42)^{\mathrm{B}}$ \\
Cmax, nmol/L & CLAMP & $103,747.1(69,725.85,137,768.35)^{\mathrm{A}}$ & $199,291.4(142,082.66,256,500.14)^{\mathrm{B}}$ \\
& CONT & $104.32 \pm 8.5^{\mathrm{A}}$ & $137.23 \pm 8.5^{\mathrm{B}}$ \\
& BAND & $81.98 \pm 9.5^{\mathrm{A}}$ & $121.91 \pm 8.5^{\mathrm{B}}$ \\
& PULL & $104.99 \pm 9.5^{\mathrm{A}}$ & $127.84 \pm 8.5^{\mathrm{B}}$ \\
Tmax, min & CLAMP & $104.54 \pm 8.5^{\mathrm{A}}$ & $124.75 \pm 8.5^{\mathrm{B}}$ \\
& CONT & $30.5(17.38,52.99)^{\mathrm{A}}$ & $31.25(17.13,16.12)^{\mathrm{B}}$ \\
& BAND & $25.42(13.47,47.26)$ & $17.82(9.98,31.25)$ \\
& PULL & $26.82(14.23,49.81)$ & $33.55(18.58,59.97)$ \\
\hline
\end{tabular}

\footnotetext{
${ }_{\mathrm{A}, \mathrm{B}}$ Indicate significant differences between age groups for a given treatment $(P \leq 0.05)$
}

${ }^{1}$ Treatments were control (CONT) or castration by banding (BAND), cut and clamp (CLAMP), or cut and pull (PULL) procedure.

absolute power across calves, thus decreasing sensitivity to errors created by differences in amplifier gain between channels. As a result, the effects of amplitude differences of noncerebral origin, such as those due to varying skull thickness or asymmetrical interelectrode distances are minimized (Bromm and Lorenz, 1998).

Based on the EEG results, 8-wk-old animals showed a more pronounced response to CONT than PULL castration, as evidenced by the lower total power of the CONT group. Furthermore, no other clear pattern of desynchronization was apparent across castration methods in this age group. Although several studies have successfully recorded EEG signals in young calves (1-10 and 12 wk and older; Takeuchi et al., 1998; Bergamasco et al., 2011), it has been suggested that

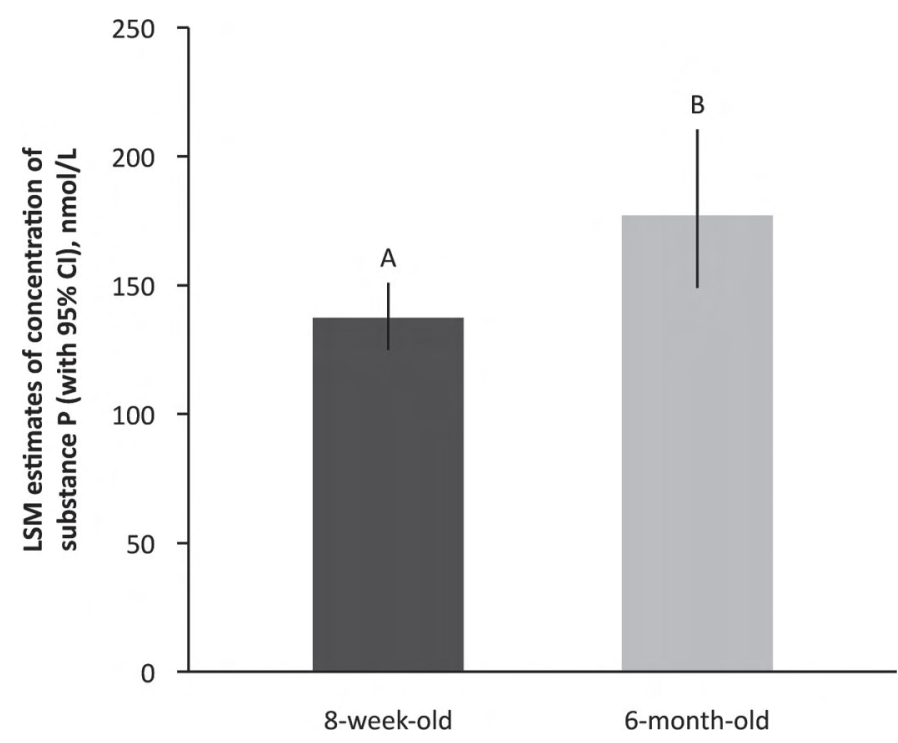

Figure 11. Least squares means estimates (and 95\% CI) for concentration of substance $\mathrm{P}(\mathrm{nmol} / \mathrm{L})$ of 8 -wk-old and 6-mo-old calves. Uppercase letters (A, B) indicate significant difference between age groups $(P \leq 0.05)$. although the brain stem function matures before birth, cortical functions continue to develop for at least the first $10 \mathrm{wk}$ of life (Takeuchi et al., 1998). Human and ruminant studies indicate a lower degree of cerebral activity accompanies neonatal pain and behavioral and physiological responses to pain in younger individuals are less than in older individuals (Holmes and Ben-Ari, 2001; Johnson et al., 2009). This is likely because the nociceptive pathways in neonates must first be primed to process pain and newborns must also learn to react to these situations (Johnson et al., 2009). It is also noteworthy that neonates exposed to pain at an early age develop a stronger hyperalgesic response to subsequent pain than older animals (McCracken et al., 2010). Taken together, these observations suggest that neural plasticity is likely higher when maturation of the neural networks in young animals is incomplete. This may help to explain why no clear pattern of desynchronization was apparent across castration methods in calves less than 8 wk of age. To the author's knowledge, this is the first published report comparing EEG responses to different castration techniques in different age groups of calves. Further studies are needed to evaluate the relationship between maturation of the nervous system and timing of painful procedures in young animals.

In contrast, the physiological response to castrationinduced pain seemed to be more clearly displayed in 6-mo-old calves, which likely have more mature neural networks than their 8-wk-old counterparts. In our study, 6-mo-old calves showed the most pronounced response to castration by CLAMP compared with CONT, as evidenced by lower total power, greater high-frequency relative power ( $\beta$ band) and lower low-frequency relative power ( $\delta$ band) of the former. Whereas all groups (CONT included) showed evidence for EEG desynchronization over time during the procedure, desynchronization was particularly apparent in 6-mo-old 
calves castrated by CLAMP relative to other castration methods as described above. In addition, 6-mo-old PULL-castrated calves had decreased low-frequency power (absolute power of $\delta$ and $\theta$ bands) and lower total power compared with 8-wk-old PULL-castrated calves. This provides additional support for the hypothesis that age-specific EEG desynchronization occurs in calves in response to castration and suggests that older calves may be more distressed by PULL castration than younger calves.

The application of these findings to support recommendations regarding the optimal method and timing of castration in calves should be done with caution. A study evaluating the effect of tail docking following castration in lambs identified a decreased pain sensation but prolonged hyperalgesia in sheep castrated at $1 \mathrm{~d}$ of age compared with those castrated at $10 \mathrm{~d}$ of age. Although lambs that were castrated earlier showed fewer pain behaviors at the time of castration, they demonstrated more pain behaviors after tail docking than lambs that were castrated later (McCracken et al., 2010). Therefore, whereas older calves may show a more robust response to acute pain following castration than younger calves, it is important to consider the possibility of early exposure to a painful procedure resulting in hyperalgesia in younger calves and subsequent higher levels of pain and discomfort. Furthermore, the absence of desynchronization across castration methods in young calves does not imply that they do not require analgesia at the time of castration. Although cortical functions in these calves are not developed enough to show the same EEG responses observed in older calves, this does not necessarily indicate they are not experiencing pain.

\section{Heart Rate Variability}

Younger calves experienced an increase in mean heart rate after castration through late recovery postcastration; a similar increase was not apparent in older calves. This observation may be related to a transient decrease of sympathetic tone during castration, which has been associated with visceral pain induced by the tearing of the spermatic cords (Stewart et al., 2010a). A study examining the effects of castration in cattle showed an increase in heart rate for calves castrated with and without local anesthetic compared with controls, suggesting increased sympathetic tone (Stewart et al., 2010a). These age-specific changes in mean heart rate over time suggest greater sympathetic tone in 8-wk-old animals compared with 6-mo-old animals. This may be due to the fact that younger calves have a physiologically higher basal heart rate than older calves due to an increased metabolic rate (Schmidt-Nielsen, 1970).
The higher NN50 observed in younger calves indicates a greater number of R-R intervals greater than $50 \mathrm{~ms}$ in length, which may be associated with slower ventricular rates (and increased vagal tone) or irregular cardiac rhythm (Nussinovitch et al., 2011). No evidence for any effect of castration method was apparent on this response.

Increased low-frequency power is indicative of increased sympathetic activity (Rajendra Acharya et al., 2006), which may be associated with increased distress. Older calves showed higher low-frequency power in the CONT and PULL groups compared with younger calves. This result suggests 6 -mo-old calves may have experienced increased distress compared with their younger counterparts when exposed to CONT or when PULL procedures.

Decreased high-frequency power is indicative of decreased parasympathetic activity (Rajendra Acharya et al., 2006). Older calves showed lower high-frequency power in the CONT and PULL groups compared with younger calves, suggesting 6-mo-old calves experienced more distress than 8-wk-old calves under CONT or when castrated by PULL. As expected, the results for high-frequency power mirrored the results for lowfrequency power as the 2 variables are natural complements of one another in defining the balance between sympathetic and vagal tones.

An increase in the low frequency to high frequency ratio indicates a shift toward increased sympathetic tone, which is frequently associated with increased distress (Rajendra Acharya et al., 2006). According to our results, older animals in the CONT and PULL groups displayed increased low frequency to high frequency ratio and, therefore, increased sympathetic tone. These calves possibly experienced increased distress compared with younger calves. Normalized low frequency to high frequency ratio followed a similar pattern as low-frequency power. This is anticipated because low-frequency power is a contributing factor to low frequency to high frequency ratio.

\section{Infrared Thermography}

Results for infrared thermography may seem contradictory with physiological expectations, as sympathetic stimulation associated with pain causes vasoconstriction, which would be anticipated to decrease temperature in the eye. However, the observed increase in temperature could also be explained by activation of the autonomic nervous system, as several researchers have hypothesized that the release of vasodilators, such as nitric oxide, occurs in response to pain or distress (Mellor et al., 2000; Stewart et al., 2010a). A study on pain due to castration examined infrared thermography 
in 4 treatment groups: control, surgical castration with no pain treatment, local anesthetic with no castration, and local anesthetic with castration (Stewart et al., 2010a). Results showed an initial decrease in maximum eye temperature followed by an increase in maximum eye temperature among calves castrated without anesthetic (Stewart et al., 2010a). In fact, for all castration treatments, maximum eye temperature was eventually increased after treatment, with the nontreated castration group showing the highest peak temperature and the control group showing the lowest peak temperature (Stewart et al., 2010a).

\section{Electrodermal Activity}

Lower electrodermal activity suggests decreased distress or less severe pain (Richardson et al., 2007) among younger calves. It should be noted, however, that several papers have reported poor reliability of the pain gauge for measuring nociception in large animals (Richardson et al., 2007; Kotschwar et al., 2009). In particular, Baldridge et al. (2011) hypothesized that mucin, electrolytes, and water secreted by eccrine sweat glands of the nasal planum may interfere with the pain gauge measurements. It is also possible that the observed electrodermal activity differences may be simply due to physiological differences between the 2 age groups (Coetzee, 2011).

\section{Cortisol}

In all castration treatments (including CONT), 8-wkold calves showed lower cortisol concentrations than older calves during the first 60 min following treatment. No further evidence for age differences was apparent past this point. This suggests that younger calves may be less acutely distressed by handling and castration procedures than their older counterparts. No evidence for differences between castration methods was noted.

We interpret cortisol AUC as total exposure to cortisol, such that increased AUC in 6-mo-old animals may be indicative of increased distress compared with 8-wkold animals, which is consistent with previous results (Mellor et al., 2000). In turn, lower Cmax in 8-wk-old calves suggests that this group of animals experienced less distress (Mellor et al., 2000). The longer duration of the cortisol peak in older calves is consistent with increased distress, as previously reported (Mellor et al., 2000).

\section{Substance $P$}

Substance P is released by sensory nerves and by a variety of non-neural sources, such as endothelial cells, macrophages, and eosinophils, and has an important function in the modulation of nociception (Rameshwar et al., 1993). Results for substance P suggest that 6-mo-old calves experienced more stress or pain than their 8-wk-old counterparts. Alternatively, these agespecific levels of substance P may be indicative of other physiological differences between the 2 age groups.

\section{CONCLUSIONS}

In conclusion, these physiological measurements indicate 8-wk-old calves reacted differently than 6-mo-old calves to handling and castration procedures. Whereas all treated and control calves showed an increased level of arousal after the time of treatment, EEG evidence suggests that 6 -mo-old calves had the most pronounced acute response to the CLAMP treatment (lower $\delta$ power, higher $\beta$ power, and lower total power compared with control). Although no clear pattern of desynchronization was evident in 8-wk-old calves in any castration treatment, younger calves showed significant differences in EEG response when treated with PULL compared with 6 -mo-old calves. These findings provide evidence that support welfare policies recommending castration at an early age, but the possibility of hyperalgesia in young animals must be considered. These results also support guidelines advocating the use of analgesic compounds at the time of surgical castration, especially in older animals.

\section{ACKNOWLEDGMENTS}

This project was supported by Agriculture and Food Research Initiative Competitive Grant number 2009-65120-05729 from the USDA National Institute of Food and Agriculture and award number T35RR007064 from the National Center for Research Resources. J. F. Coetzee was supported by Agriculture and Food Research Initiative Competitive Grant number 2008-35204-19238 from the USDA National Institute of Food and Agriculture. This project was in part funded by Kansas State University, College of Veterinary Medicine, Departments of Anatomy and Physiology and Clinical Sciences. Special thanks to Kara Smith, Colleen Hill, the Kansas State University Beef Cattle Research Center staff, and the student workers who made this project possible. Thank you to Juan S. Velez, DVM, of Aurora Organic Dairy for the donation of younger calves and to Christopher Schuetze, Land O' Lakes Inc. (Shoreview, MN) for the partial donation of milk replacer.

\section{REFERENCES}

AVMA (American Veterinary Medical Association). 2012. Welfare implications of the castration of cattle. Accessed October 9, 
2012. https://www.avma.org/KB/Resources/Backgrounders/ Pages/castration-cattle-bgnd.aspx.

Baldridge, S. L., J. F. Coetzee, S. S. Dritz, J. B. Reinbold, R. Gehring, J. Havel, and B. Kukanich. 2011. Pharmacokinetics and physiologic effects of intramuscularly administered xylazine hydrochloride-ketamine hydrochloride-butorphanol tartrate alone or in combination with orally administered sodium salicylate on biomarkers of pain in Holstein calves following castration and dehorning. Am. J. Vet. Res. 72:1305-1317. http://dx.doi.org/10.2460/ajvr.72.10.1305.

Bergamasco, L., J. F. Coetzee, R. Gehring, L. Murray, T. Song, and R. A. Mosher. 2011. Effect of intravenous sodium salicylate administration prior to castration on plasma cortisol and electroencephalography parameters in calves. J. Vet. Pharmacol. Ther. 34:565-576. http://dx.doi.org/10.1111/j.1365-2885.2011.01269.x.

Bosch, J. A., E. J. C. De Geus, D. Carroll, A. D. Goedhart, L. A Anane, J. J. Veldhuizen van Zanten, E. J. Helmerhorst, and K. M. Edwards. 2009. A general enhancement of autonomic and cortisol responses during social evaluative threat. Psychosom. Med. 71:877-885. http://dx.doi.org/10.1097/PSY.0b013e3181baef05.

Bromm, B., and J. Lorenz. 1998. Neurophysiological evaluation of pain. Electroencephalogr. Clin. Neurophysiol. 107:227-253. http://dx.doi.org/10.1016/S0013-4694(98)00075-3.

Cardo, E., K. Chellew, R. M. Doctor, J. Fornes, G. Garcia-Banda, and V. Meisel. 2011. Prosocial personality traits and adaptation to stress. Soc. Behav. Personal. 39:1337-1348. http://dx.doi. org/10.2224/sbp.2011.39.10.1337.

Chase, C. C., Jr., R. E. Larsen, R. D. Randel, A. C. Hammond, and E. L. Adams. 1995. Plasma cortisol and white blood cell responses in different breeds of bulls: A comparison of two methods of castration. J. Anim. Sci. 73:975-980.

Coetzee, J. F. 2011. A review of pain assessment techniques and pharmacological approaches to pain relief after bovine castration: Practical implications for cattle production within the United States. Appl. Anim. Behav. Sci. 135:192-213. http://dx.doi. org/10.1016/j.applanim.2011.10.016.

Coetzee, J. F., R. Gehring, A. C. Bettenhausen, B. V. Lubbers, S. E. Toerber, D. U. Thomson, B. KuKanich, and M. D. Apley. 2007. Attenuation of acute plasma cortisol response in calves following intravenous sodium salicylate administration prior to castration. J. Vet. Pharmacol. Ther. 30:305-313. http://dx.doi.org/10.1111/ j.1365-2885.2007.00869.x

Coetzee, J. F., B. V. Lubbers, S. E. Toerber, R. Gehring, D. U. Thomson, B. J. White, and M. D. Apley. 2008. Plasma concentrations of substance $\mathrm{P}$ and cortisol in beef calves after castration or simulated castration. Am. J. Vet. Res. 69:751-762. http://dx.doi. org/10.2460/ajvr.69.6.751.

Coetzee, J. F., R. A. Mosher, B. KuKanich, R. Gehring, B. Robert, J. B. Reinbold, and B. J. White. 2012. Pharmacokinetics and effect of intravenous meloxicam in weaned Holstein calves following scoop dehorning without local anesthesia. BMC Vet. Res. 8:153. http://dx.doi.org/10.1186/1746-6148-8-153.

Coetzee, J. F., A. L. Nutsch, L. A. Barbur, and R. M. Bradburn. 2010. A survey of castration methods and associated livestock management practices performed by bovine veterinarians in the United States. BMC Vet. Res. 6:12 http://dx.doi.org/10.1186/17466148-6-12.

Critchley, H. D. 2005. Neural mechanisms of autonomic, affective, and cognitive integration. J. Comp. Neurol. 493:154-166. http:// dx.doi.org/10.1002/cne.20749.

DeVane, C. L. 2001. Substance P: A new era, a new role. Pharmacotherapy 21:1061-1069. http://dx.doi.org/10.1592/ phco.21.13.1061.34612.

FASS (Federation of Animal Science Societies). 2010. Guidelines for the care and use of agricultural animals in research and teaching. Accessed Oct. 9, 2012. http://www.fass.org.

FDA (Food and Drug Administration). 2006. development of target animal safety and effectiveness data to support approval of nonsteroidal anti-inflammatory drugs (NSAIDs) for use in animals. Accessed Oct. 9, 2012. http://www.fda.gov/downloads/Animal Veterinary/GuidanceComplianceEnforcement/Guidancefor Industry/ucm052663.pdf.
Grandin, T. 1997. Assessment of stress during handling and transport. J. Anim. Sci. 75:249-257.

Holmes, G. L., and Y. Ben-Ari. 2001. The neurobiology and consequences of epilepsy in the developing brain. Pediatr. Res. 49:320 325. http://dx.doi.org/10.1203/00006450-200103000-00004.

Johnson, C. B. 2007. New approaches to identifying and measuring pain. Pages 1-10 in Proc. Aust. Anim. Welf. Strategy Sci. Summit Pain Pain Manag., Massey University, Palmerston North, New Zealand. Australian Government Department of Agriculture, Fisheries and Forestry (DAFF), Canberra City.

Johnson, C. B., S. P. Sylvester, K. J. Stafford, S. L. Mitchinson, R. N. Ward, and D. J. Mellor. 2009. Effects of age on the electroencephalographic response to castration in lambs anaesthetized with halothane in oxygen from birth to 6 weeks old. Vet. Anaesth. Analg. 36:273-279. http://dx.doi.org/10.1111/j.1467-2995.2009.00448.x.

Kent, J. E., V. Molony, and I. S. Robertson. 1993. Changes in plasma cortisol concentration in lambs of three ages after three methods of castration and tail docking. Res. Vet. Sci. 55:246-251. http:// dx.doi.org/10.1016/0034-5288(93)90088-W.

Kotschwar, J. L., J. F. Coetzee, D. E. Anderson, R. Gehring, B. KuKanich, and M. D. Apley. 2009. Analgesic efficacy of sodium salicylate in an amphotericin B-induced bovine synovitis-arthritis model. J. Dairy Sci. 92:3731-3743. http://dx.doi.org/10.3168/ jds.2009-2058.

McCracken, L., N. Waran, S. Mitchinson, and C. B. Johnson. 2010 Effect of age at castration on behavioural response to subsequent tail docking in lambs. Vet. Anaesth. Analg. 37:375-381. http:// dx.doi.org/10.1111/j.1467-2995.2010.00547.x.

Mellor, D. J., C. J. Cook, and K. J. Stafford. 2000. Quantifying some responses to pain as a stressor. Pages 171-198 in The Biology of Animal Stress-Basic Principles and Implications for Animal Welfare. G. P. Moberg and J. A. Mench, ed. CAB International Publishing, Wallingford, UK.

Minton, J. E. 1994. Function of the hypothalamic-pituitary-adrenal axis and the sympathetic nervous system in models of acute stress in domestic farm animals. J. Anim. Sci. 72:1891-1898.

Murrell, J. C., and C. B. Johnson. 2006. Neurophysiological techniques to assess pain in animals. J. Vet. Pharmacol. Ther. 29:325-335. http://dx.doi.org/10.1111/j.1365-2885.2006.00758.x.

NRC. 2012. Welcome to the National Resources Council. Accessed Oct. 9, 2012. http://nationalacademies.org/nrc/.

Nussinovitch, U., K. P. Elishkevitz, K. Kaminer, M. Nussinovitch, S. Segev, B. Volovitz, and N. Nussinovitch. 2011. The efficiency of 10 -second resting heart rate for the evaluation of short-term heart rate variability indices. Pacing Clin. Electrophysiol. 34:1498 1502. http://dx.doi.org/10.1111/j.1540-8159.2011.03178.x.

Rajendra Acharya, U., K. P. Joseph, N. Kannathal, C. M. Lim, and J. S. Suri. 2006. Heart rate variability: A review. Med. Biol. Eng. Comput. 44:1031-1051. http://dx.doi.org/10.1007/s11517-0060119-0.

Rameshwar, P., D. Ganea, and P. Gascon. 1993. In vitro stimulatory effect of substance P on hematopoiesis. Blood 81:391.

Richardson, C. A., L. Niel, M. C. Leach, and P. A. Flecknell. 2007. Evaluation of the efficacy of a novel electronic pain assessment device, the Pain Gauge ${ }^{\circledR}$, for measuring postoperative pain in rats. Lab. Anim. 41:46-54. http://dx.doi.org/10.1258/002367707779399455.

Rust, R. L., D. U. Thomson, G. H. Lonergan, M. D. Apley, and J. C. Swanson. 2007. Effect of different castration methods on growth performance and behavior responses of postpubertal beef bulls. Bovine Pract. 41:111-118.

Saul, J. P. 1990. Beat-to-beat variations of heart rate reflect modulation of cardiac autonomic outflow. News Physiol. Sci. 5:32-37.

Schmidt-Nielsen, K. 1970. Energy metabolism, body size, and the problem of scaling. Proc. Am. Physiol. Soc. 29; 4:1524-1533. http:// www.uvm.edu/ pdodds/files/papers/others/1970/schmidt-nielsen1970a.pdf.

Sequeira, H., P. Hot, L. Silvert, and S. Delplanque. 2009. Electrical autonomic correlates of emotion. Int. J. Psychophysiol. 71:50-56. http://dx.doi.org/10.1016/j.ijpsycho.2008.07.009. 
Stafford, K. 2007. Alleviating the pain caused by the castration of cattle. Vet. J. 173:245-247. http://dx.doi.org/10.1016/j. tvj1.2005.11.002

Stewart, M., G. A. Verkerk, K. J. Stafford, A. L. Schaefer, and J. R. Webster. 2010a. Noninvasive assessment of autonomic activity for evaluation of pain in calves, using surgical castration as a model J. Dairy Sci. 93:3602-3609. http://dx.doi.org/10.3168/jds.20103114.

Stewart, M., J. R. Webster, K. J. Stafford, A. L. Schaefer, and G. A. Verkerk. 2010b. Technical Note: Effects of an epinephrine infusion on eve temperature and heart rate variability in bull calves. J. Dairy Sci. 93:5252-5257. http://dx.doi.org/10.3168/jds.20103448.

Takeuchi, T., K. Sitizyo, and E. Harada. 1998. Analysis of the electroencephalogram in growing calves by use of power spectrum and cross correlation. Am. J. Vet. Res. 59:777-781.

Task Force of the European Society of Cardiology the North American Society of Pacing Electrophysiology (Task Force). 1996. Heart rate variability: Standards of measurement, physiological interpre- tation, and clinical use. Circulation 93:1043-1065. http://dx.doi. org/10.1161/01.CIR.93.5.1043.

Ting, S. T. L., B. Earley, J. M. L. Hughes, and M. A. Crowe. 2003. Effect of ketoprofen, lidocaine local anesthesia, and combined xylazine and lidocaine caudal epidural anesthesia during castration of beef cattle on stress responses, immunity, growth and behavior. J. Anim. Sci. 81:1281-1293.

von Borell, E., J. Langbein, G. Després, S. Hansen, C. Leterrier, J Marchant-Forde, R. Marchant-Forde, M. Minero, E. Mohr, A Prunier, D. Valance, and I. Veissier. 2007. Heart rate variability as a measure of autonomic regulation of cardiac activity for assessing stress and welfare in farm animals - A review. Physiol. Behav. 92:293-316. http://dx.doi.org/10.1016/j.physbeh.2007.01.007.

Wildman, B. K., C. M. Pollock, O. C. Schunicht, C. W. Booker, P. T. Guichon, G. K. Jim, T. J. Pittman, T. Perrett, P. S. Morley, C. W. Jones, and S. R. Lee. 2006. Evaluation of castration technique, pain management and castration timing in young feedlot bulls in Alberta. Bovine Pract. 39:47-49. 